\title{
Specific detection of fungal pathogens by I8S rRNA gene PCR in microbial keratitis
}

\author{
Zunaina Embong ${ }^{1}$, Wan Hazabbah Wan Hitam ${ }^{1}$, Chan Yean Yean'2, \\ Nur Haslindawaty Abdul Rashid ${ }^{3}$, Balqis Kamarudin ${ }^{4}$, Siti Khaironi \\ Zainal Abidin ${ }^{5}$, Sabariah Osman², Zainul F Zainuddin ${ }^{3}$ and \\ Manickam Ravichandran*2
}

\begin{abstract}
Address: ${ }^{1}$ Department of Ophthalmology, School of Medical Sciences, Universiti Sains Malaysia, Malaysia, ${ }^{2}$ Department of Medical Microbiology and Parasitology, School of Medical Sciences, Universiti Sains Malaysia, Malaysia, ${ }^{3}$ School of Health Sciences, Universiti Sains Malaysia, Malaysia, ${ }^{4}$ Universiti Malaya, Malaysia and ${ }^{5}$ Universiti Teknologi Malaysia, Malaysia

Email: Zunaina Embong - zunaina@yahoo.com; Wan Hazabbah Wan Hitam - mravic@yahoo.com; Chan Yean Yean - yeancyn@yahoo.com; Nur Haslindawaty Abdul Rashid - lindawaty_rashid@yahoo.com; Balqis Kamarudin - futterbly_21@yahoo.com; Siti Khaironi Zainal Abidin - pudica85@yahoo.com; Sabariah Osman - mravic@streamyx.com; Zainul F Zainuddin - zainulfz@kb.usm.my; Manickam Ravichandran*-mravic@kb.usm.my

* Corresponding author
\end{abstract}

Published: 29 April 2008

BMC Ophthalmology 2008, 8:7 doi:10.1186/147|-2415-8-7

This article is available from: http://www.biomedcentral.com/I47I-24I5/8/7

(c) 2008 Embong et al; licensee BioMed Central Ltd.

This is an Open Access article distributed under the terms of the Creative Commons Attribution License (http://creativecommons.org/licenses/by/2.0), which permits unrestricted use, distribution, and reproduction in any medium, provided the original work is properly cited.
Received: 23 September 2007

Accepted: 29 April 2008

\begin{abstract}
Background: The sensitivity and specificity of I8S rRNA polymerase chain reaction (PCR) in the detection of fungal aetiology of microbial keratitis was determined in thirty patients with clinical diagnosis of microbial keratitis.

Methods: Corneal scrapings from patients were used for Gram stain, culture and PCR analysis. PCR was performed with primer pairs targeted to the I8S rRNA gene. The result of the PCR was compared with conventional culture and Gram staining method. The PCR positive samples were identified by DNA sequencing of the internal transcribed spacer (ITS) region of the rRNA gene. Main outcome measures were sensitivity and specificity of PCR in the detection of fungus in corneal keratitis.

Results: Combination of microscopy and culture gave a positive result in II of 30 samples of microbial keratitis. PCR detected 10 of I I samples that were positive by conventional method. One of the 19 samples that was negative by conventional method was positive by PCR. Statistical analysis revealed that the PCR to have a sensitivity of $90.9 \%$ and specificity of $94.7 \%$ in the detection of a fungal aetiology in microbial keratitis.
\end{abstract}

Conclusion: PCR is a rapid, sensitive and useful method to detect fungal aetiology in microbial keratitis.

\section{Background}

Microbial keratitis is a serious ocular infection that can cause corneal scarring and opacification. The principal known causes of microbial keratitis are bacteria and fungi [1-5]. The incidence of fungal keratitis varies across the United States, ranging from less than 1\% in New York, 
$17 \%$ in Texas and 35\% in Florida [6]. A wide range of fungi have been isolated. Fusarium and Aspergillus are the most common pathogens, representing $40 \%$ and $20 \%$, respectively [7]. In Malaysia, only isolated cases of fungal keratitis have been reported; however, in the neighboring country of Singapore, the most commonly identified organisms in keratitis samples were Fusarium sp. (52\%) and Aspergillus flavus (17\%) [8,9].

The incidence of fungal keratitis has increased; inadequate therapy and inaccurate or delayed diagnosis have led to generally poor visual outcomes $[10,11]$. Its diagnosis remains a difficult problem, although the history and clinical appearance may suggest fungal keratitis. Conventional microbiological detection of fungus in clinical samples requires 2 days to one week [12]. Gram stain and culture techniques occasionally fail in the detection of fungal keratitis. The main reason for this phenomenon is the presence of a relatively small number of causative infectious pathogens in the scraping specimens, which in many cases are non-viable for culture [13].

The basis for effective treatment is rapid diagnosis of the disease and identification of its causative agent. The use of the polymerase chain reaction (PCR) offers great advantage compared with conventional microbiological testing [13-16]. Pan-fungal primers specific for the conserved sequence of $18 \mathrm{~S}$ and $28 \mathrm{~S}$ rRNA gene common to all fungi have been used to detect fungal pathogen in clinical specimens [17]. The 28S rRNA gene PCR evaluation was carried out by Anand et al. in 2000 [17]. The 18S rRNA genebased PCR for the detection of airborne fungi has been reported, but this method requires specific oligonucleotide probes and hybridization [18]. The aim of this study is to evaluate a PCR method based on a new set of primers targeted to $18 \mathrm{~S}$ rRNA gene for rapid detection of pan-fungal aetiology in microbial keratitis.

\section{Methods}

\section{Reference strains}

Various filamentous fungi (Penicillium sp, Fusarium sp, Alternaria sp, Aspergillus versicolor, Aspergillus fumigatus), yeast (Candida albicans) and bacteria (Staphylococcus aureus, Enterococcus sp., Pseudomonas aeruginosa, Haemo- philus influenzae) were obtained from the Department of Medical Microbiology and Parasitology, Hospital Universiti Sains Malaysia, Kelantan, Malaysia. Human DNA was also included in the collection.

\section{(i) DNA extraction}

DNA was extracted from the sample using a commercial Nucleospin DNA extraction kit according to manufacturer's instructions with some modification (Clontech, CA, USA). Briefly, the samples were transferred to a $1.5 \mathrm{ml}$ microcentrifuge tube containing 30 to $50,0.5 \mathrm{~mm}$ diameter glass beads and $0.2 \%$ SDS (sodium dodecyl sulfate). Cell destruction was achieved by vortexing the microcentrifuge tube for 15 minutes. Six hundred microliters of sorbitol buffer ( $1 \mathrm{M}$ sorbitol, $100 \mathrm{mM}$ EDTA, $14 \mathrm{mM} \beta$ mercaptoethanol) and $10 \mu \mathrm{l}$ (200 units) of lyticase (Sigma, Missouri, USA) were added and the solution was incubated at $30^{\circ} \mathrm{C}$ for 30 minutes. The mixture was then centrifuged at $6000 \mathrm{rpm}$ for 10 minutes. The spheroplast pellet was resuspended in lysis buffer (Nucleospin Kit) and $25 \mu \mathrm{l}$ of proteinase $\mathrm{K}(20 \mathrm{mg} / \mathrm{ml})$ was added, mixed by vortexing and incubated at $56^{\circ} \mathrm{C}$ overnight. The sample was then centrifuged at 10,000 rpm for 5 minutes. The supernatant was transferred to a fresh $1.5 \mathrm{ml}$ microcentrifuge tube following the steps recommended by the kit. The extracted DNA from the standard fungal cultures were quantified spectrophotometrically at OD260/280 nm with ratios between 1.7 to 1.8 .

The analytical sensitivity of the primers was evaluated by PCR amplification with serial diluted concentrations (range: $10 \mathrm{ng}-1 \mathrm{fg}$ ) of purified genomic DNA isolated from Aspergillus versicolor as a representative fungal species.

\section{(ii) Primer design}

The 18S rRNA gene was chosen as the target gene for this study. The 18S rRNA gene sequences from Aspergillus sp., Candida sp. and Fusarium sp. were downloaded from GenBank or EMBL databases. A set of unique primers were designed based on the conserved region in all fungal species. To verify the specificity of the designed primers, the BLAST program at the NCBI website was employed to search the primers in short, near exact sequences. Table 1

Table I: The sequences of primers and their relative binding sites on I8S rRNA gene of representative species

\begin{tabular}{ccccc}
\hline Primer name & Sequence 5'............3' & Location (position of base pair) & \\
\cline { 3 - 5 } & & $\begin{array}{c}\text { Aspergillus niger (GenBank } \\
\text { accession no. D63697) }\end{array}$ & $\begin{array}{c}\text { Fusarium solani (GenBank } \\
\text { accession no. E17084) }\end{array}$ & $\begin{array}{c}\text { Candida sp. (GenBank accession } \\
\text { no. EFI20586) }\end{array}$ \\
\hline PFPRIM-F3 & $\begin{array}{c}\text { GACTCAACACGGGGA } \\
\text { AACT }\end{array}$ & $1149-1167$ & $1222-1240$ & $1134-1152$ \\
PFPRIM-R4 & $\begin{array}{c}\text { ATTCCTCGTTGAAGA } \\
\text { GCA }\end{array}$ & $1522-1539$ & $1605-1622$ & $1509-1526$
\end{tabular}


shows the positions of the primers used in this study with respect to the representative sequences obtained from GenBank (Aspergillus niger accession no. D63697, Fusarium solani accession no. E17084 and Candida sp. accession no. EF120586). Primers were synthesized by First Base Laboratories (Kuala Lumpur, Malaysia). Using ITS1, ITS4 and ITS86 primers, a semi-nested PCR was carried out on the samples that were positive by $18 \mathrm{~S}$ rRNA PCR [14]. The fungal ribosomal $18 \mathrm{~S}$ rRNA gene and internal transcribed spacer (ITS) region with primer binding locations are shown in Figure 1.

\section{(iii) $P C R$}

PCR reactions for the detection of the fungal keratitis were set up in a clean room with pipettes reserved specifically for this purpose. The PCR reactions were performed in 20 $\mu \mathrm{l}$ volumes containing $2 \mu \mathrm{l}$ of the genomic DNA sample, $1 \times$ PCR buffer containing $750 \mathrm{mM}$ Tris- $\mathrm{HCl}(\mathrm{pH} 8.8$ at $\left.25^{\circ} \mathrm{C}\right), 200 \mathrm{mM}\left(\mathrm{NH}_{4}\right)_{2} \mathrm{SO}_{4}, 0.1 \%$ Tween $20 ; 2.5 \mathrm{mM}$ $\mathrm{MgCl}_{2} ; 0.16 \mathrm{mM}$ dNTP Mix; $20 \mathrm{pmol}$ of forward and reverse primers and $0.75 \mathrm{U}$ Taq DNA polymerase (MBI, Fermentas, Lithuania). The mixes were overlaid with 2 drops of mineral oil. Amplification was carried out in a thermal cycler (Eppendorf Mastercycler 5330) with initial denaturation at $95^{\circ} \mathrm{C}$ for 4 minutes, followed by 30 cycles of denaturation at $95^{\circ} \mathrm{C}$ for 30 seconds, annealing at $55^{\circ} \mathrm{C}$ for primer pair PFPRIM-F3 and PFPRIM-R4 for 30 seconds, and extension at $72^{\circ} \mathrm{C}$ for 30 seconds. The thermal cycles were terminated by a final extension for 5 minutes at $72{ }^{\circ} \mathrm{C}$. Purified Aspergillus versicolor genomic DNA served as a positive control and deionised sterile water served as a negative control. The analysis of PCR products were performed on $1 \%$ agarose gels. The molecular weight markers Generuler $100 \mathrm{bp}$ and $1 \mathrm{~kb}$ DNA ladder (Fermentas, Lithuania) were used and the gel was run at 100 volt for 45 minutes at room temperature. The PCR products were stained with ethidium bromide and visualized by an image analyzer (ChemiImager 5500, Alpha Innotech, CA, USA).

\section{Clinical study \\ (i) Collection of specimens}

Sample size $(\mathrm{n}=30)$ for this cross-sectional study was calculated using Single Proportion Calculator Version 1.0 [19] based on $27 \%$ prevalence [20] and $88 \%$ assay specificity [21] with $95 \%$ confidence interval and $6 \%$ precision.

Samples were obtained from patients with microbial keratitis in Hospital Universiti Sains Malaysia and Hospital Kota Bharu for a period of 16 months. Viral keratitis, noninfected corneal ulcer (neutrophic keratitis, chemical burn) and patients less than 12 years old were excluded from the study. Patients' clinical presentation and complications were recorded (Table 2).

Thirty cases of microbial keratitis were investigated in this study. Patients' ages ranged from 14 to 89 years of age; $66.7 \%$ were male and $33.3 \%$ were female. Clinical features suggestive of fungal keratitis included feathery margin (11 patients, 36.7\%), a dry texture (10 patients, $33.3 \%$ ), and satellite lesions (7 patients, $23.3 \%$ ). Two patients presented with corneal melting: one patient with graft rejection following penetrating keratoplasty who developed microbial keratitis after exposure to vegetative foreign body and one patient with corneal melting due to post couching (Table 2).

This study was carried out after obtaining the approval from the Ethics committee, School of Medical Sciences, Universiti Sains Malaysia, as per Helsinki declaration. Samples of corneal scraping were obtained from 30 patients (30 eyes) with clinical diagnosis of microbial keratitis. All patients were informed regarding the procedure with written consent. Corneal scrapings were obtained by scraping the edge of the corneal ulcer with a sterile kimura spatula after instillation of topical anaesthesia $(0.4 \%$ novesin). The procedure was done under a slit lamp biomicroscope. First scraped specimen was stirred in $150 \mu \mathrm{l}$ of deionised sterile water in a $1.5 \mathrm{ml}$ sterile tube for PCR analysis. Second scraped specimen was

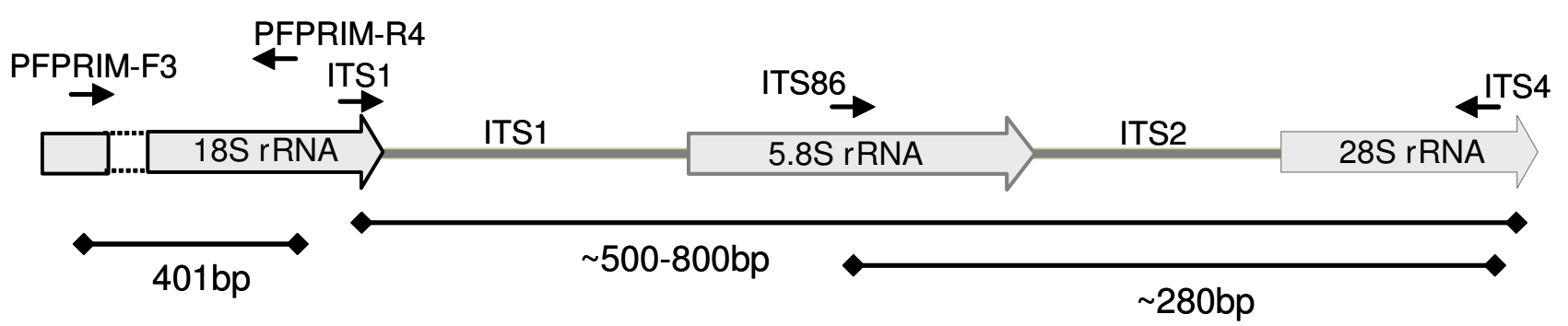

Figure I

Schematic representation of the fungal ribosomal I 8S rRNA gene and ITS regions with primer binding locations. ITS- Internal transcribed spacer region. 
Table 2: Risk factors, presentation, clinical features and laboratory diagnosis of keratitis

\begin{tabular}{|c|c|c|c|c|c|c|c|c|c|c|c|c|c|}
\hline Patient No & Trauma & Contact lens & $\begin{array}{l}\text { Size of lesion } \\
(\mathrm{mm})\end{array}$ & Margin & $\begin{array}{c}\text { Dry } \\
\text { texture }\end{array}$ & Satellite & Conj. Inj & AC rx & Hypopyon & Gram stain & Culture & PCR & DNA Sequencing (\%) \\
\hline 1 & Veg FB & No & $8 \times 6$ & Feathery & Yes & No & Yes & Yes & Yes & Hyphae & Fusarium sp. & + & Fusarium solani (97\%) \\
\hline 2 & Non-veg FB & No & $8 \times 8$ & Feathery & Yes & Yes & Yes & Yes & Yes & Hyphae & Fusarium sp. & + & Cladosporium sp. (98\%) \\
\hline 3 & No & No & $3 \times 4$ & Feathery & No & Yes & Yes & Yes & Yes & Hyphae & Fusarium sp. & + & Fusarium sp. (97\%) \\
\hline 4 & Non-veg FB & No & $3 \times 2$ & Feathery & Yes & No & Yes & Yes & Yes & Hyphae & Fusarium sp. & + & Fusarium solani (97\%) \\
\hline 5 & No & No & $9 \times 9$ & No & No & Yes & Yes & Yes & Yes & Hyphae & Fusarium sp. & + & Fusarium solani (99\%) \\
\hline 6 & Veg FB & No & $1 \times 2$ & No & No & No & Yes & Yes & No & Hyphae & No growth & + & Aspergillus flavus (96\%) \\
\hline 7 & Non-veg FB & No & $1 \times 1$ & No & No & No & Yes & Yes & No & Hyphae & No growth & + & Trichosporon asahii (95\%) \\
\hline 8 & No & No & $3 \times 5$ & Feathery & Yes & No & Yes & Yes & No & Hyphae & No growth & + & Fusarium solani $(87 \%)$ \\
\hline 9 & No & No & $7 \times 6$ & Feathery & Yes & No & Yes & Yes & Yes & Hyphae & Fusarium sp. & + & Glomerella cingulata (98\%) \\
\hline 10 & Non-veg FB & No & $4 \times 5$ & Feathery & No & Yes & Yes & Yes & No & No organism & Fusarium sp. & + & Fusarium sp. (97\%) \\
\hline 11 & Veg FB & No & $9 \times 9$ & No & No & No & Yes & Yes & Yes & GNB & P. aeruginosa & No & ND \\
\hline 12 & No & Yes & $2 \times 2$ & No & No & No & Yes & Yes & Yes & GNB & P. aeruginosa & No & ND \\
\hline 13 & Veg FB & No & $6 \times 5$ & No & No & No & Yes & Yes & Yes & GNB & P. aeruginosa & No & ND \\
\hline 14 & No & Yes & $4 \times 3$ & No & No & No & Yes & Yes & Yes & No organism & P. aeruginosa & No & ND \\
\hline 15 & No & No & $10 \times 10$ & Melt & Melt & Melt & Yes & Yes & Yes & No organism & No growth & No & ND \\
\hline 16 & Veg FB & No & $2 \times 3$ & No & Yes & No & Yes & Yes & Yes & GPC & S. aureus & No & ND \\
\hline 17 & No & Yes & $5 \times 4$ & Feathery & Yes & No & Yes & Yes & Yes & No organism & P. aeruginosa & No & ND \\
\hline 18 & Non-veg FB & No & $2 \times 2$ & No & No & No & Yes & Yes & No & GPC & S. pneumoniae & No & ND \\
\hline 19 & Non-veg FB & No & $8 \times 6$ & Feathery & Yes & No & Yes & Yes & Yes & No organism & No growth & No & ND \\
\hline 20 & Veg FB & No & $7 \times 7$ & Melt & Melt & Melt & Yes & Yes & Yes & No organism & No growth & No & ND \\
\hline 21 & No & Yes & $3 \times 3$ & No & No & No & Yes & Yes & No & No organism & P. aeruginosa & No & ND \\
\hline 22 & No & No & $8 \times 8$ & No & No & No & Yes & Yes & Yes & GPC & Group A Streptococci & No & ND \\
\hline 23 & Veg FB & No & $2 \times 1$ & No & No & No & Yes & Yes & Yes & No organism & No growth & No & ND \\
\hline 24 & Non-veg FB & No & $2 \times 3$ & Feathery & No & Yes & Yes & Yes & Yes & No organism & No growth & No & ND \\
\hline 25 & No & No & $1 \times 1$ & No & No & No & Yes & Yes & No & No organism & No growth & No & ND \\
\hline 26 & No & No & $1 \times 1$ & No & No & No & Yes & Yes & No & No organism & No growth & No & ND \\
\hline 27 & Veg FB & No & $2 \times 2$ & No & Yes & Yes & Yes & Yes & No & No organism & No growth & No & ND \\
\hline 28 & Non-veg FB & No & $2 \times 3$ & No & No & No & Yes & Yes & No & No organism & No growth & + & Fusarium sp. (97\%) \\
\hline 29 & No & Yes & $2 \times 2$ & No & No & No & Yes & No & No & No organism & P. aeruginosa & No & ND \\
\hline 30 & Veg FB & No & $4 \times 2$ & Feathery & Yes & Yes & Yes & Yes & No & No organism & Fungus NS & No & ND \\
\hline
\end{tabular}

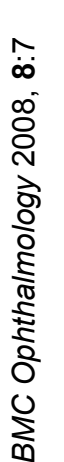

Veg FB - Vegetative foreign body, Conj. Inj. - Conjunctival injection, AC rx - Anterior chamber reaction, GNB - Gram negative bacillus, GPC - Gram Positive cocci, NS -Non sporulating fungus and ND - Not done. 
cultured onto agar and incubated at $37^{\circ} \mathrm{C}$ for identification. Third scraped specimen was placed on glass slide for gram staining.

\section{(ii) Microscopy and culture}

Gram and Giemsa stains were used on representative smears from all clinical specimens and examined under a magnification of $400 \times$ and $1000 \times$, respectively. Clinical specimens were cultured at $37^{\circ} \mathrm{C}$ on blood agar, chocolate agar, Mac Conkey agar, and Thayer Martin agar and at $30^{\circ} \mathrm{C}$ for Sabouraud's agar under aerobic and anaerobic conditions.

\section{(iii) DNA extraction}

Corneal tissue genomic DNA was extracted using the commercial Nucleospin DNA extraction kit according to manufacturer's instructions with some modification (Clontech, CA, USA) as described previously. The final volume of the DNA extracted from the corneal samples was $100 \mu \mathrm{l} ; 2 \mu \mathrm{l}$ of this DNA was used for PCR.

\section{(iv) I8S rRNA-based PCR assay}

The PCR analysis and amplification profile were carried out as described previously. The DNA extracted from patients' samples was tested and the results were compared with conventional diagnostic methods (Table 2).

\section{(v) Sequencing of ITS2 region for species identification of PCR} detected fungi

Positive samples of $18 \mathrm{~S}$ rRNA PCR were selected for further species confirmation by DNA sequencing. Primers ITS1, ITS4 and ITS 86 were used to amplify the ITS2 region by semi-nested PCR [14]. The PCR products were sequenced using an automated DNA sequencer at Tech Dragon Ltd (Hong Kong, China) and analyzed with the BLAST program provided by the National Center for Biotechnology Information (NCBI) to confirm the fungal species.

\section{Results}

\section{Primer design}

After alignment and visualization of the conserved region, primer pair PFPRIM-F3 and PFPRIM-R4 was selected and used (Table 1).

\section{Analytical sensitivity and specificity evaluation of I8S rRNA-based PCR assay using reference strains}

On the basis of the 18S rRNA sequence region, a product of $395 \pm 6$ bp was amplified by PCR with primer pair PFPRIM-F3 and PFPRIM-R4 from all 6 yeasts and filamentous fungi reference strains of medically important fungal species. None of the 4 bacterial reference strains were positive by PCR amplification (Figure 2). The specificity of the $395 \pm 6$ bp fragment was verified by DNA sequencing and analysis. No amplification was observed with human

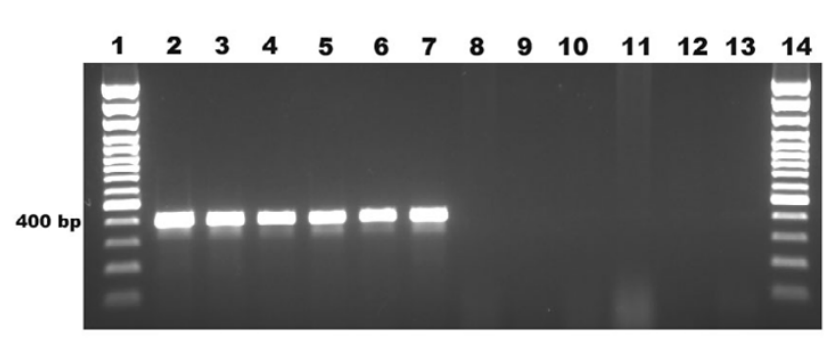

Figure 2

Specificity of I 8S rRNA PCR in yeasts, filamentous fungi and bacterial strains. Lane I, 100 bp plus marker; lane 2,Candida albicans; lane 3, Penicillium sp.; lane 4, Fusarium sp.; lane 5, Alternaria sp.; lane 6, Aspergillus versicolor; lane 7, Aspergillus fumigatus; lane 8 Staphylococcus aureus; lane 9 Enterococcus sp.; lane 10 Pseudomonas aeruginosa; lane II, Haemophilus influenzae; lane 12, Human DNA; lane 13, negative control and lane 14, 100 bp plus marker.

DNA and negative control (Figure 2). The sensitivity of the 18S rRNA PCR assay allowed detection of as little as 100 fg of A. versicolor genomic DNA by visualization on the agarose gel electrophoresis (Figure 3 ).

\section{Diagnostic sensitivity and specificity evaluation of $18 \mathrm{~S}$ rRNA-based PCR assay using corneal scraping clinical samples}

In the 30 patients with microbial keratitis, a positive fungal aetiology was detected in 11 patients (36.6\%) by PCR (Table 2). PCR was considered positive for fungi when there was presence of $395 \pm 6$ bp PCR product band on agarose gel electrophoresis using PFPRIM-F3/PFPRIM-R4 (Figure 4). Of the 30 patients, conventional Gram stain method yielded positive results in 9 patients $(30.0 \%) .8$ patients $(26.7 \%)$ were detected by the culture method.

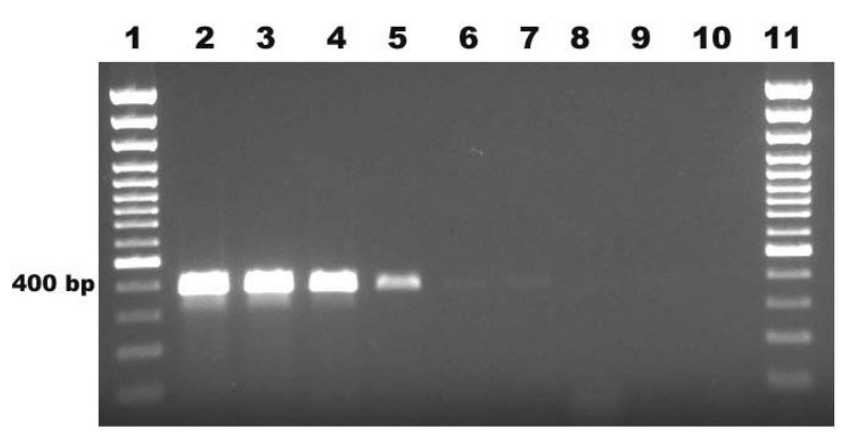

Figure 3

Sensitivity of PCR at the DNA level using I0-fold dilutions of Aspergillus versicolor DNA. Lane I, 100 bp plus marker; lane 2, 10 ng; lane 3, I ng; lane 4, 100 pg; lane 5, 10 pg; lane 6,I pg; lane 7, 100 fg; lane 8, 10 fg; lane 9, I fg; lane 10 , negative control and lane $\mathrm{I} I$, 100 bp plus marker. 


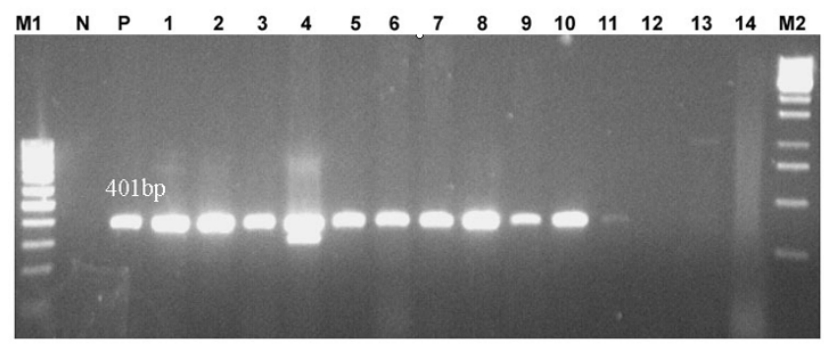

Figure 4

Detection in clinical samples using I8S rRNA PCR. Lane $\mathrm{MI}, 100$ bp plus marker; lane $\mathrm{N}$, negative control; lane $\mathrm{P}$, positive control; lane $\mathrm{I}-14$, clinical samples and lane $\mathrm{M} 2$, I kb marker.

The most common genus isolated by culture was Fusarium sp, accounting for 7 patients (23\%). One patient showed growth of non-sporulating fungus (Table 2).

\section{DNA sequencing of ITS2 region for species identification}

The species of the fungus in the PCR positive samples were identified by DNA sequencing of the internal transcribed spacer (ITS) region of the rRNA gene. Segments of 500 to $800 \mathrm{bp}$ of the entire ITS regions, including partial 5.8S rRNA and 28S rRNA, were amplified from the 11 PCR positive samples using one primer pair, ITS1 and ITS4 (Figure 1). The semi-nested ITS2 region PCR of approximately 280 bp was amplified using primer pair, ITS86 and ITS4 (Figure 1). Among the 11 PCR positive samples, Fusarium sp. was identified in 7 samples; Cladosporium sp., Aspergillus flavus, Trichosporon asahii, and Glomerella cingulata were also identified. Two of the PCR positive samples that were identified as Fusarium sp. by culture method were identified as Glomerella cingulata and Cladosporium by DNA sequencing. This could be due to mixed infection or contamination of the PCR. Combination of microscopy and culture gave a positive result in 11 of 30 samples of microbial keratitis. PCR detected 10 out of 11 samples that were positive by conventional method. One of the 19 samples that were negative by conventional methods was positive by PCR (Table 2).

\section{Statistical analysis}

A statistical analysis revealed that the PCR has a sensitivity of $90.9 \%$ and specificity of $94.7 \%$ to detect fungal aetiology in microbial keratitis (Table 3 ).

\section{Discussion}

In this study, PCR was evaluated for its efficacy in the detection of fungal pathogens in corneal scrapings using characterized reference strains. Human genomic DNA was included in the analytical specificity evaluation of the PCR
Table 3: Statistical analysis of I8S rRNA PCR diagnostic evaluation

\begin{tabular}{lccc}
\hline I 8S rRNA PCR assay & \multicolumn{2}{c}{ Microscopy and Culture } & Total \\
\cline { 2 - 3 } & Positive & Negative & \\
\hline Positive & 10 & 1 & 11 \\
Negative & 1 & 18 & 19 \\
Total & 11 & 19 & 30 \\
\hline
\end{tabular}

a. True positive $=10$, false positive $=1$, false negative $=1$, true negative $=18$.

b. This leads to estimates of sensitivity $=0.91(95 \% \mathrm{Cl}=0.59$ to I.00), specificity $=0.95(95 \% \mathrm{Cl}=0.74$ to $\mathrm{I} .00)$ and a diagnostic odds ratio (DOR) of 180 (7.8 to 8195.8$)$.

c. The positive likelihood ratio $(\mathrm{LR}+)$ is $17.3(95 \% \mathrm{Cl}=2.5$ to $1 \mathrm{I7.4})$ and the negative likelihood ratio (LR-) is $0.10(95 \% \mathrm{Cl}=0.03$ to 0.36$)$.

to rule out the non-specific amplification of the patient genomic DNA from the corneal scraping.

In this study $18 \mathrm{~S}$ rRNA specific primers that amplify medically important fungi were selected and used. The $18 \mathrm{~S}$ rRNA gene is a multi-copy gene that is slowly evolving and highly conserved among fungi, making it an attractive target for the detection of fungus in clinical specimens. Detection of fungal aetiology by $18 \mathrm{~S}$ rRNA targeted PCR will be useful in early diagnosis of fungal keratitis and could help in early initiation of antifungal therapy. ITS2 based seminested PCR followed by sequencing was used to identify the species of fungus. ITS has been used to detect fungal pathogens in ocular infections by DNA sequencing and single-stranded conformation polymorphism (SSCP) [14,22].

The current study demonstrates that $18 \mathrm{~S}$ rRNA-based PCR has high degrees of analytical sensitivity (100 fg) and specificity $(100 \%)$ for the detection of a wide range of medical significant fungi. Our primers are based on the conserved region of $18 \mathrm{~S}$ rRNA gene which is designed to detect wide range of fungal strains with the PCR product size of $395 \pm 6$ bp. However, the ITS based PCR amplifies product size varies between 500 to 800 bp [14]. The difference in product size of ITS primer based PCR often caused difficulty in interpretation the positive from nonspecific band in the agarose gel. The non-specific amplification or positive fungal identification can be confirmed only after further sequencing of the ITS PCR product. In addition, ITS primers require two tubes nested PCR method, which is tedious and prone for cross-contamination. The PFPRIM primers based-PCR used in our study is a single tube pan-fungal PCR which can confirm fungal infection. Chen et al. in 2000 have used ITS2 region specific primers to detect fungal species based on PCR product size (ranging from 237 to 429 bp) identification by 
capillary electrophoresis and restriction polymorphism [23].

The most common initial laboratory procedure done in diagnosis of fungal keratitis is microscopic examination. In this study, a positive microscopic examination was observed in $30 \%$ (9) of patients. The percentage of positive stains showing fungal elements was similar to studies in South Florida, in which 33\% of Gram stains were positive [20]. Culture yielded positive results in $26.7 \%$ of the samples and PCR was positive in $36.6 \%$. The findings of this study agree with those of Lohmann et al. [24] and Anand et al. [17], demonstrating high analytical specificity and sensitivity of the PCR method compared with the conventional method. PCR based test showed improved detection of fungal aetiology in microbial keratitis. Conventionally, culture has been used as 'gold standard' to detect fungal pathogens, but takes 2 days to several weeks for final identification. The main problem with culture from corneal scraping specimens is the small amount of material that can be obtained for diagnosis, increasing the risk of false-negative results. Additionally, some fungal species cannot be cultured or grow slowly and have fastidious growth requirements. This may explain the negative culture results in 3 of the samples used in this study.

The PCR diagnostic test had a sensitivity of $90.9 \%$. PCR detected 10 of 11 samples that were positive by conventional method. One of the samples that were negative by PCR is a case of microbial keratitis due to non-sporulating fungus. This could be due to insufficient fungal elements present in corneal scraping or due to sequence variation of $18 \mathrm{~S}$ rRNA gene of this fungus. It is possible that different layers of corneal scraping were used for culture, Gram stain and PCR. Hence, the corneal scraping submitted for PCR may have had insufficient fungal elements relative to the samples submitted for culture and Gram stain.

When compared to the Gram stain and PCR, the specificity of PCR was $94.7 \%$ with one false positive. However, this sample was found to be positive for Fusarium sp. by DNA sequencing. The culture is positive only if the sample contains viable organisms, while a PCR based test will detect both viable and non-viable organisms.

By DNA sequencing of the ITS2 region, we could identify the fungal species [23]. Our results agree with the work of Fitzsimons [7], demonstrating Fusarium sp. as the predominated aetiology in ocular fungal keratitis infection. DNA sequencing identified two samples that were misidentified by culture method. Less common organisms, such as Cladosporium sp., Aspergillus flavus, Trichosporon asahii and Glomerella cingulata, were identified by DNA sequencing. The role of Cladosporium sp., Trichosporon asa- hii and Glomerella cingulata in keratitis needs to be investigated.

In most cases of keratitis, the most important laboratory information that the ophthalmologist needs to know is whether the infectious agent is fungal or bacterial. They often hesitate to initiate antifungal therapy in fungal culture negative cases due to the risk of drug associated toxicity. Positive PCR results that are available earlier than culture will justify the use of antifungal agents promptly, resulting in improved visual outcome. This current data agrees with the study by Anand et al. [17] and confirms the efficacy of the PCR assay compared to conventional methods of diagnosis in the clinical setting.

\section{Conclusion}

This study has demonstrated the efficacy of the 18S rRNA gene to detect fungal pathogen in clinical samples. This PCR based test is a rapid, sensitive and a useful method to detect fungal aetiology in microbial keratitis when compared to standard laboratory techniques. Further studies with larger sample size are needed to refine the technique, to calculate sensitivity and specificity, and to establish the value of the technique in managing patients with microbial keratitis.

\section{Conflict of interest}

The authors declare that they have no competing interests.

\section{Authors' contributions}

ZE carried out the molecular genetic and biochemical studies, participated in contribution of conception, design, acquisition of data, analysis and interpretation of data, was involved in drafting of the manuscript, revised it critically for important intellectual content and gave final approval of the version to published. WHWH participated in contribution of conception, design and gave final approval of the version to publish. CYY participated in the design of the study, analysis and interpretation of data; was involved in drafting the manuscript and gave final approval of the version to publish.NH, BK, SKA and SO carried out the molecular genetic and biochemical studies, acquisition of data, analysis and interpretation of data and gave final approval of the version to publish.ZFZ participated in contribution of conception, design, analysis and interpretation of data, was involved in drafting the manuscript and revised it critically for important intellectual content. MR participated in contribution of conception, design, acquisition of data, analysis and interpretation of data, was involved in drafting the manuscript, revised it critically for important intellectual content and gave final approval of the version to be published. 


\section{Acknowledgements}

This work was funded by Universiti Sains Malaysia (USM) short-term grant. We would like to acknowledge Assoc. Prof. Dr. Syed Hatim Noor, Unit Biostatistics and Research Methodology, School of Medical Sciences, USM for statistical consultation.

\section{References}

I. Alfonso E MS Fox M.J, Foster R.K.: Ulcerative keratitis associated with contact lens wear. Am J Ophthalmol 1986, I 01 :429-433.

2. Brook I. FEH: Aerobic and anaerobic microbiology of keratitis. Ann Ophthalmol 1999, 31:21-26.

3. Leck AK, Thomas PA, Hagan M, Kaliamurthy J, Ackuaku E, John M, Newman MJ, Codjoe FS, Opintan JA, Kalavathy CM, Essuman V, Jesudasan CA, Johnson GJ: Aetiology of suppurative corneal ulcers in Ghana and south India, and epidemiology of fungal keratitis. Br J Ophthalmol 2002, 86( I I): |2| I-1215.

4. Musch D.C SA Meyer R.F.: Demographic and predisposing factors in corneal ulceration. Arch Ophthalmol I 983, I 0 I: I545-I 548.

5. Wilhelmus K.R RNM Font R.A, Hamill M.B, Jones D.B.: Fungal keratitis in contact lens wearers. Am J Ophthalmol 1988, 106:708-7| 4.

6. Asbell P SS: Ulcerative keratitis. Survey of $\mathbf{3 0}$ years laboratory experience. Arch Ophthalmol 1982, 100:77-80.

7. Fitzsimons R. PAL: Miconazole and ketoconazole as a satisfactory first- line treatment for keratomycosis. Am J Ophthalmol 1986, I01:605-608.

8. Singh H, Jamal F, Marahakim MN, Song CC: Fusarium solani keratitis. First report from Malaysia. Med J Malaysia 198I, 36(2):89-9I.

9. Wong TY, Fong KS, Tan DT: Clinical and microbial spectrum of fungal keratitis in Singapore: a 5-year retrospective study. Int Ophthalmol 1997, 2 I(3): I27-130.

10. Loeffler J HH Brauchle U, Schumacher U, Einsele H.: Comparison between plasma and whole blood specimens for detection of Aspergillus DNA by PCR. Journal of Clinical Microbiology 2000:3830-3833.

II. Nicola F: [Non-viral infectious keratitis: predisposing factors, etiologic agents and laboratory diagnosis]. Rev Argent Microbiol 2005, 37(4):229-239.

12. Ishibashi $Y$. HS Maatsumoto Y.: Direct examination vs culture of biopsy specimens for the diagnosis of keratomycosis. Am Journal Ophthalmol 1987, I 03:636-640.

13. Hendolin PH PL Kahkola PK, Anttila VJ, Malmerg H, Richardson M, Ylikoski ].: Panfungal PCR and Multiplex liquid hybridization for detection of fungi in tissue specimens. Journal of Clinical Microbiology 2000:4186-4192.

14. Ferrer C, Colom F, Frases S, Mulet E, Abad JL, Alio JL: Detection and identification of fungal pathogens by PCR and by ITS2 and 5.8S ribosomal DNA typing in ocular infections. J Clin Microbiol 200I, 39(8):2873-2879.

15. Makimura K MSY and Yamguchi H.: Detection of a wide range of medically important fungi by the polymerase chain reaction. J Med Microbiol 1994, 40:358-364.

16. Rickerts V, Mousset S, Lambrecht E, Tintelnot K, Schwerdtfeger R, Presterl E, Jacobi V, Just-Nubling G, Bialek R: Comparison of histopathological analysis, culture, and polymerase chain reaction assays to detect invasive mold infections from biopsy specimens. Clin Infect Dis 2007, 44(8): I078-1083.

17. Anand A, Madhavan H, Neelam V, Lily T: Use of polymerase chain reaction in the diagnosis of fungal endophthalmitis. Ophthalmology 200I, I08(2):326-330.

18. Wu Z, Tsumura Y, Blomquist G, Wang XR: I 8S rRNA gene variation among common airborne fungi, and development of specific oligonucleotide probes for the detection of fungal isolates. Appl Environ Microbiol 2003, 69(9):5389-5397.

19. Sample size for sensitivity \& specificity studies [http:// www.kck.usm.my/ppsg/statistical resources/ samplesize forsensitivity specificitystudiesLinNaing.xls]

20. Rosa R. H. MD Alfonso E. C.: The changing spectrum of fungal keratitis in South Florida. Ophthalmology 1994, I 0 I: 1005-1013.

21. Alexandrakis G JS and Gloor P.: Diagnosis of Fusarium keratitis in an animal model using the polymerase chain reaction. $\mathrm{Br}$ J Ophthalmol 1998, 82:306-31 I.

22. Kumar M, Shukla PK: Use of PCR targeting of internal transcribed spacer regions and single-stranded conformation polymorphism analysis of sequence variation in different regions of rrna genes in fungi for rapid diagnosis of mycotic keratitis. J Clin Microbiol 2005, 43(2):662-668.

23. Chen YC, Eisner JD, Kattar MM, Rassoulian-Barrett SL, LaFe K, Yarfitz SL, Limaye AP, Cookson BT: Identification of medically important yeasts using PCR-based detection of DNA sequence polymorphisms in the internal transcribed spacer 2 region of the rRNA genes. J Clin Microbiol 2000, 38(6):2302-23l0.

24. Lohmann CP, Heeb M, Linde HJ, Gabel VP, Reischl U: Diagnosis of infectious endophthalmitis after cataract surgery by polymerase chain reaction. I Cataract Refract Surg 1998, 24(6):82|-826.

\section{Pre-publication history}

The pre-publication history for this paper can be accessed here:

\section{http://www.biomedcentral.com/1471-2415/8/7/prepub}

Publish with Biomed Central and every scientist can read your work free of charge

"BioMed Central will be the most significant development for disseminating the results of biomedical research in our lifetime. "

Sir Paul Nurse, Cancer Research UK

Your research papers will be:

- available free of charge to the entire biomedical community

- peer reviewed and published immediately upon acceptance

- cited in PubMed and archived on PubMed Central

- yours - you keep the copyright

Submit your manuscript here:

http://www.biomedcentral.com/info/publishing_adv.asp
BioMedcentral 